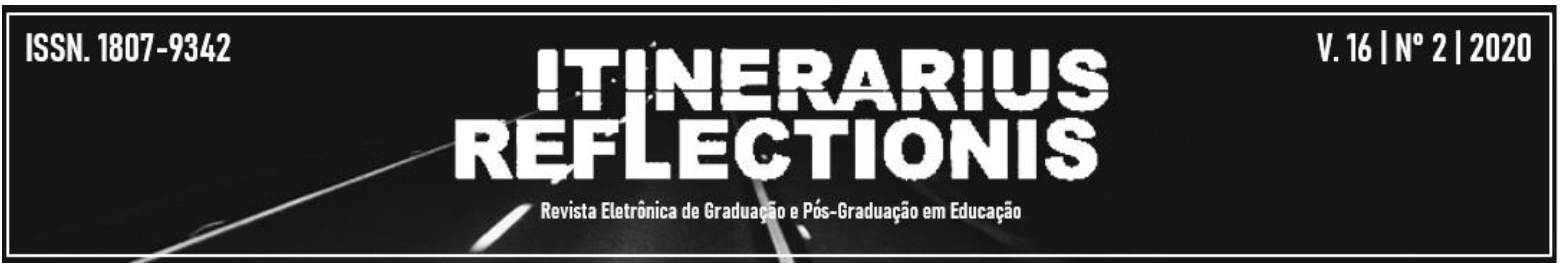

\title{
A universidade e a formação docente no contexto da inclusão escolar: uma releitura de freire e saviani
}

\author{
Romulo Renato Cruz Santana ${ }^{1}$ \\ Vanderlei Balbino da Costa ${ }^{2}$
}

\begin{abstract}
Resumo A presente pesquisa é resultado de um estudo contextualizado à luz do pensamento educacional brasileiro, na disciplina Pensamento Educacional, do curso de Mestrado em Educação pela Universidade Federal de Goiás - Regional Jataí. No desenvolvimento desse artigo, a intenção foi alcançar os seguintes objetivos: analisar a contribuição da disciplina para a formação do pensamento educacional brasileiro, apontar a relevância do pensamento educacional de Saviani e Freire e evidenciar o papel da universidade na formação do docente no contexto da Inclusão Escolar. A opção metodológica nesse estudo foi pela pesquisa qualitativa, baseando em referenciais bibliográficos e documentos oficiais que regem a Inclusão Escolar. As reflexões trouxeram a percepção de que a universidade pode ser um espaço de constante aprendizado para os docentes em formação aliada à necessidade de oportunizar uma Inclusão Escolar, emancipatória e libertadora, fazendo com que as pessoas com deficiência tenham oportunidades justas e isonômicas de acesso ao conhecimento.
\end{abstract}

Palavras-chave: Universidade. Ensino Superior. Formação docente. Inclusão Escolar.

University and teacher traning in the contexto of school inclusion: a rereading of freire e saviani

\begin{abstract}
This research is the result of a study contextualized in the light of the Brazilian educational thought, in the discipline of Educational Thought, of the Master's degree in Education by Federal University of Goiás (UFG) - Regional Jataí. Our intention in developing this article was to achieve the following objectives: to analyze the contribution of the discipline to the formation of Brazilian educational thought, to point out the relevance of the educational thinking of Saviani and Freire and to highlight the role of the university in the teacher training within the context of School Inclusion. The methodological option in this study was the qualitative research, based on bibliographic references and official documents that govern the School Inclusion. The reflections have brought the perception that the university can be a space of constant learning for the teachers in formation allied to the need to provide a School Inclusion truly emancipatory and liberating, allowing people with disabilities to have fair and isonomic opportunities of access to knowledge.
\end{abstract}

Keywords: University. Higher Education. Teacher training. School Inclusion.

\footnotetext{
${ }^{1}$ Centro Universitário de Mineiros e Faculdade Morgana Potrich: romulo@unifimes.edu.br

${ }^{2}$ Universidade Federal de Goiás (UFG/ Regional Jataí) vanderleibalbino@ gmail.com
} 


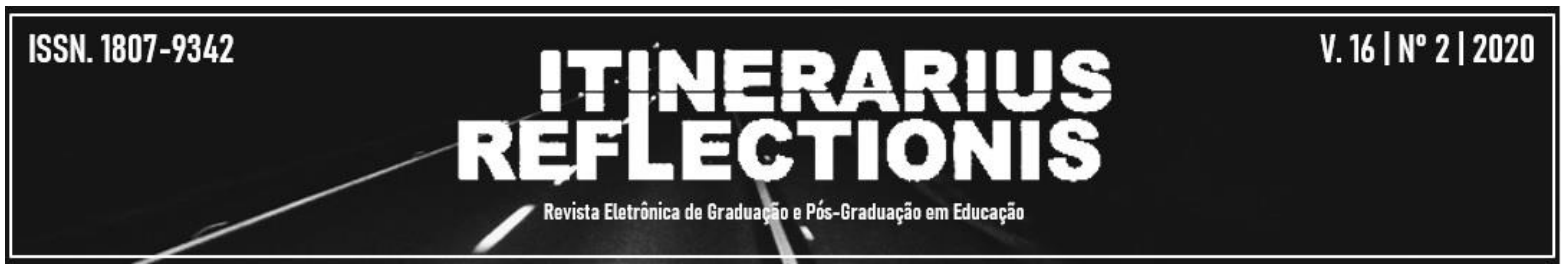

\section{INTRODUÇÃO}

A proposta do presente artigo é analisar o contexto da formação do docente de ensino superior, no âmbito da Inclusão Escolar, através de uma revisão bibliográfica sobre os temas e textos relacionados à disciplina Pensamento Educacional, componente de integralização da matriz curricular do Curso de Mestrado em Educação, do Programa de Pós-Graduação em Educação, da Universidade Federal de Goiás - Regional Jataí.

Ao longo de um semestre, foram abordados vários tópicos significantes para a construção e formação do pensamento educacional brasileiro na aludida disciplina e, como produto final, o presente artigo trará uma reflexão a respeito da contribuição de dois dos principais autores desse legado educacional, a saber, Dermeval Saviani, contextualizado no âmbito da sua Pedagogia Histórico-Crítica, bem como Paulo Freire na seara da Pedagogia do Oprimido, sem não menos deixar de relacioná-los com a contribuição da essência Marxista nos programas de Pós-Graduação em Educação.

Passemos, então, para uma reflexão acerca da contribuição do pensamento de Saviani e Freire para com a formação de docentes, mais precisamente no ensino superior, sem deixar de elucidar a importância do papel da universidade nessa sistemática, trazendo um viés marxista na análise dos textos de acordo com a trajetória metodológica traçada através de uma revisão bibliográfica.

A metodologia adotada pelo autor aponta, possivelmente, um problema de pesquisa: Quais são as contribuições do pensamento educacional de Freire e Saviani para a formação docente no contexto da Inclusão Escolar? Qual a relação desse questionamento com o projeto de pesquisa no Programa de Mestrado em Educação da UFG - Regional Jataí, o qual compreende a Inclusão Escolar na formação do docente de Ensino Superior?

Tal artigo possui como objetivos: analisar a contribuição da disciplina para a formação do pensamento educacional brasileiro, apontar a relevância do pensamento educacional de Saviani e Freire, e evidenciar o papel da universidade na formação do docente no contexto da Inclusão Escolar. 


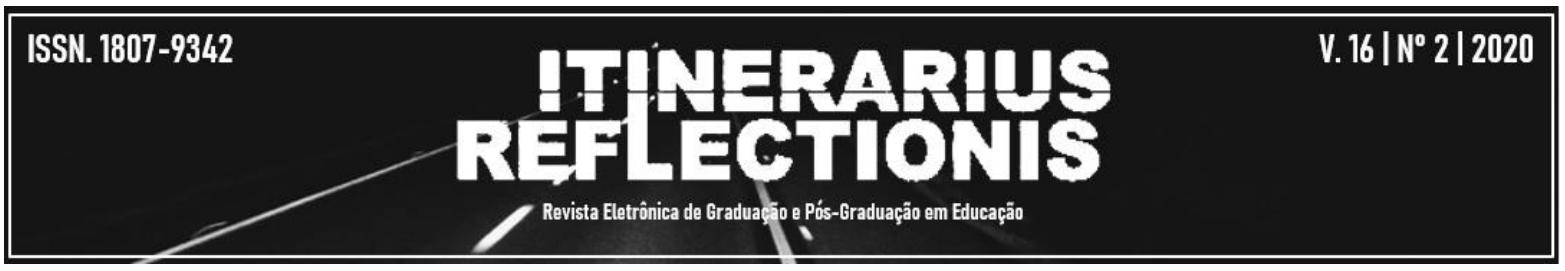

A opção metodológica utilizada neste estudo reflexivo foi a pesquisa qualitativa, tendo como apoio Ludke e André (p. 11, 1986), ao afirmarem que "a pesquisa qualitativa tem o ambiente natural como sua fonte direta de dados e o pesquisador como seu principal instrumento".

Em seu teor, a formação de professores é analisada através de uma breve abordagem do contexto da Inclusão Escolar em linhas sublimes, contextualizando-a com a Declaração de Salamanca (1994), bem como na ótica da Lei $\mathrm{n}^{\circ}$ 13.146/2015. No presente artigo, não menos diferente, a opção adotada foi fazer um link entre Paulo Freire, Dermeval Saviani e o não menos importante pensamento marxista, para que, sob esse olhar, possa haver um entendimento sobre a sistemática e dialética realidade que envolve o contexto da formação docente no Brasil, ainda que em breves linhas e a influência que o celeiro de aprendizado que chamamos de universidade pode proporcionar.

\section{A contribuição do pensamento educacional de Saviani e Freire para a formação do}

\section{Docente de Ensino Superior}

Durante a revisão bibliográfica pôde-se perceber que, dentre as teorias analisadas através das leituras dos textos, a que mais pode contribuir para a formação teórica do professor, ao longo dos anos, é a proposta de Dermeval Saviani, que na sua Pedagogia Histórico-Crítica deixa também evidenciado o porquê de receber tal nomenclatura.

O termo "Histórico" sugere, nesta perspectiva, que a educação também exerce interferências sobre a sociedade, podendo contribuir para a sua transformação, ao passo que a expressão "Crítica" traz consigo traços de uma consciência da determinação exercida pela sociedade sobre a educação e para a educação.

Dermeval Saviani elucida, na maior parte de sua produção científica, que esta concepção surge das necessidades postas pela prática de muitos profissionais da área da educação, visto que as pedagogias tradicionais, nova e tecnicista, não traziam na sua essência características históricas, pois resta evidente que lhes faltava a consciência dos condicionantes histórico-sociais da educação Saviani (2007). 


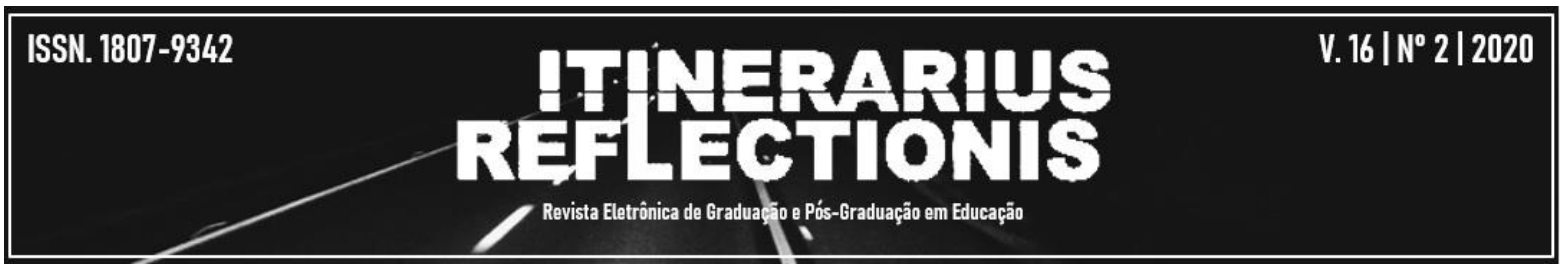

Pode-se destacar que é na realidade escolar onde se enraíza a proposta pedagógica sugerida por Saviani (2007), uma Pedagogia que tem como objetivo resgatar a importância da escola e seu papel na reorganização do processo educativo, sem deixar despercebido o saber sistematizado por via do qual se define a especificidade do saber escolar.

Não se pode deixar de mencionar que esta é uma teoria imprescindível para a compreensão do contexto da educação brasileira, uma vez que evidencia um método diferenciado de trabalho, perfazendo-se por passos que são providenciais para o desenvolvimento do educando, sendo o primeiro passo a prática real, o segundo a problematização, o terceiro a instrumentalização e, por fim, a prática social.

Através de sua obra, Saviani (2005) objetiva estimular a atividade e a iniciativa do professor, oportunizando o diálogo dos alunos entre si e com o docente, sem deixar de levar em consideração o diálogo com a cultura historicamente acumulada, levando em conta os interesses dos alunos, os ritmos e níveis de aprendizagem, assim como o desenvolvimento psicológico, sem perder do alcance das vistas a sistematização lógica do conhecimento, sua ordenação e gradação para efeitos do processo de transmissão e consequente assimilação dos conteúdos cognitivos.

Uma proposta sistematizada e historicamente relevante ao analisar o contexto educacional, nos impulsiona a questionar sobre a real finalidade dela para os indivíduos e, nesse contexto, a única reflexão que vem à mente é a propositura de junção da essência de Saviani (2005) com a ideia libertadora de Paulo Freire (2005), uma vez que os indivíduos devem ser submetidos a processos de formação educacional, sabendo e tendo consciência do seu real papel na sociedade, o que acaba lhe libertando do aprisionamento da massificação da classe trabalhadora.

Aproveitando a ideia de diálogo proposta por Saviani (2005), pode-se compreender que a dialogicidade está intimamente servindo de elo entre este autor e Freire, quando sugere o diálogo com elemento a favorecer a superação de barreiras na construção do conhecimento. Sob esse olhar é que se apoia toda a teoria freiriana, uma vez que, segundo sua essência, o diálogo nasce na prática da liberdade, enraizando na existência do sujeito e trazendo uma proposta comprometida com a vida, que se historiciza no seu contexto. 


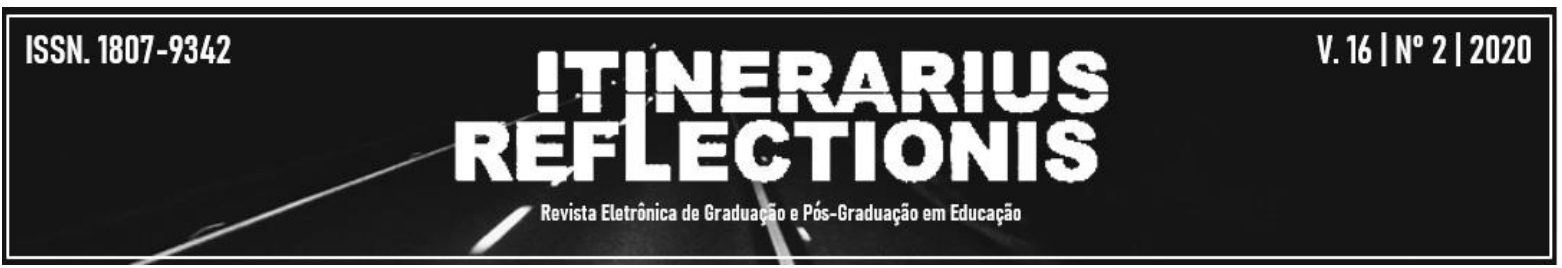

Na sua obra editada há 40 anos, após apresentar a justificativa do título Pedagogia do Oprimido, Freire (2005), ao exemplificar a educação bancária onde inexiste o diálogo, intensifica essa realidade nos capítulos 3 e 4 com um olhar voltado à ação dialógica e antidialógica. Entretanto, a dialogicidade é a essência da educação como mola propulsora para a prática da liberdade, haja vista que o diálogo é tratado como um fenômeno humano segundo Paulo Freire, pois "nos revela como algo que já poderemos dizer ser ele mesmo: a palavra. Mas, ao encontrarmos a palavra, na análise do diálogo, como algo mais que um meio para que ele se faça, se nos impõe buscar, também seus elementos constitutivos” Freire (p. 89, 2005).

Para esse teórico da educação não há palavra que não seja práxis ou que não provenha da práxis, pois, ao pronunciá-la, estamos pronunciando e, consequentemente, transformando o mundo.

Na ideia da dialogicidade estarão sempre presentes as dimensões da ação e da reflexão. Ao pronunciar o mundo, inevitavelmente mostra-se que humanamente existimos e, se existimos, pode-se agir e modificar esse mundo que nos é dado.

Frente à contribuição desses autores da educação brasileira, é relevante propor dois questionamentos: qual a influência que essas duas teorias podem exercer no processo de formação docente? Como se daria esse fluxo quando nos reportamos à inclusão dentro do ensino superior? Percebe-se que poderia passar dias e horas a propor as possíveis resoluções a esses casos, porém, numa via simples, mas não menos de mão dupla, é conveniente compreender se a Universidade teria ou não um papel importante na formação do professor, enquanto esta representa o seio de relações interpessoais na construção do conhecimento.

\section{A função da universidade no processo de formação docente}

No contexto do ensino superior é importante haver a consciência de que o acesso ao mesmo é pautado em políticas que tentam acompanhar o desenvolvimento socioeconômico do país, evidenciando desde a última década um acentuado aumento no quadro de ingressantes, provenientes do ensino médio, como também os cidadãos que permanecem por determinado tempo sem convivência no ambiente de estudos, o que põe o docente em constante obrigação de se adaptar à realidades múltiplas e mutáveis. 




Quando o objetivo é compreender o aumento da oferta de ensino, deve-se analisar a expansão da educação superior no Brasil, partindo da necessidade de compreender o REUNI Programa de Apoio a Planos de Reestruturação e Expansão das Universidades Federais que, no ano de 2003, direcionou as ações públicas da educação focadas na multiplicação e interiorização das universidades federais.

Com o intuito de alcançar o maior número de pessoas no ensino superior, mas, sem critérios realmente comprometidos com a qualidade do ensino, em 2004 foi criado pelo Governo Federal o PROUNI - Programa Universidade para Todos, que apresentou à sociedade novas oportunidades para os jovens além do FIES - Fundo de Financiamento Estudantil, já existente, o qual se tornou mais acessível em 2010, segundo Carmo et al., (2014).

Dessa forma, as autoridades permitiram a criação de políticas estruturadas e pautadas na expansão, galgando, inclusive, oferecer vagas em maior número, tanto no público, mas, muito mais, ao aprovar os diversos cursos de universidades privadas, sem se preocupar com o aumento e aprimoramento dos programas de formação continuada, para oportunizar a esse público os docentes capacitados de forma condizente com os ditames idealizados nos projetos políticos pedagógicos dos cursos amplamente aprovados e em funcionamento nesse atual contexto.

Dentro dessa realidade, o docente em formação ou os programas específicos já existentes, se mostram impulsionados a analisar a relação do seu contexto com as mais variadas situações vivenciadas no dia a dia, do planejamento à execução do conteúdo em sala de aula para seu público-alvo.

Vivemos em uma sociedade capitalista e a perspectiva a respeito das políticas educacionais é um objetivo que, para ser alcançado, faz-se necessário desenvolver um estudo a respeito da concepção marxista sobre a educação e, ao mesmo tempo, entender porque essa relação sujeito e objeto se mostra de forma que o segundo é sempre o regente, mas ao perder força na sua aplicabilidade dá espaço para o sujeito ser o centro das atenções, sob o ponto de vista prático e real.

Nesse contexto e com relação a essa prioridade atribuída ao sujeito é que se vê o ponto central do pensamento moderno a respeito da educação, onde o pensamento de Marx se opõe 


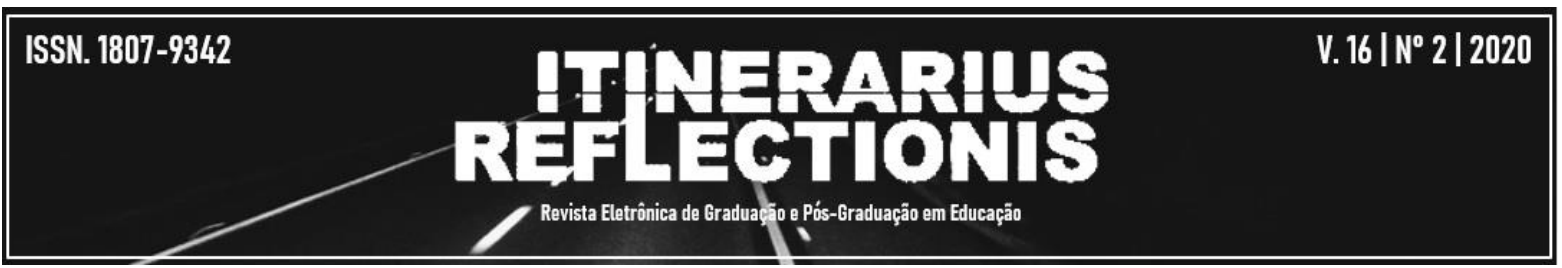

com maior intensidade. Ao perceber-se abandonada a prioridade do ser sob o aspecto ontológico, cada pensamento crítico está liberto para atribuir à visão marxista o sentido que lhe convier, na maioria das vezes com uma fidelidade intelectual e mais coerente, pois isso deve ser tratado com muita cautela no ambiente acadêmico de graduação superior.

Para Marx (1989), o real sentido dado ao sujeito no meio social, converge para o entendimento que o sentido da radicalidade ou sede de reforma imprime a essas palavras um sentido político. Contudo, o mesmo pensador ainda defende que a justificativa dessa postura radical está, antes de tudo, ligada à ontologia, quando defende que a análise da natureza do ser social é que lhe permite alcançar a essência desse mesmo ser.

Em O Capital, Marx (1989), elucida que o trabalho é um intercâmbio entre a natureza e o homem, de forma que este, através de suas funções laborativas, oportuniza ao seu grupo social os bens necessários à própria sobrevivência humana. Trazer essa teoria para o contexto dessa temática é a forma mais profunda de compreender que esse intercâmbio precisa ser resgatado em atenção à necessidade de sintetizar a subjetividade e objetividade, com relação à intimidade que se mostra entre a consciência e a realidade objetiva natural, na qual o docente se insere no cenário do ensino superior.

$\mathrm{Na}$ ótica da formação docente, é preciso refletir sobre a forma que o pensamento Marxista poderá contribuir para que não só o planejamento das políticas públicas, como também a teoria/práxis, oportunizem no ensino superior que o docente consiga se blindar do todo e compreender a visão geral sobre de onde veio, do ponto de vista de sua especialização, e o que deve fazer com relação ao seu papel para com as turmas que leciona.

Dado esse primeiro passo, o docente deverá internalizar e evidenciar em suas metodologias de ensino as suas fragilidades profissionais e, somente a partir deste ponto, alcançar individualidades dessa diversidade de mentes que envolvem seu respectivo grupo de alunos de graduação.

Entretanto, é importante salientar que o crescimento da oferta de vagas anda paralelo à outra realidade na qual o Brasil ainda precisa experimentar o avanço a largos passos. Veja-se, pois, quando refere-se à Inclusão Escolar, sobretudo porque esta é constante alvo de produção científica, mas ainda necessita de aprofundamento e consolidação de conceitos e teorias, de forma a nos tornar num futuro, quem sabe, sujeitos de uma realidade solidificada. 


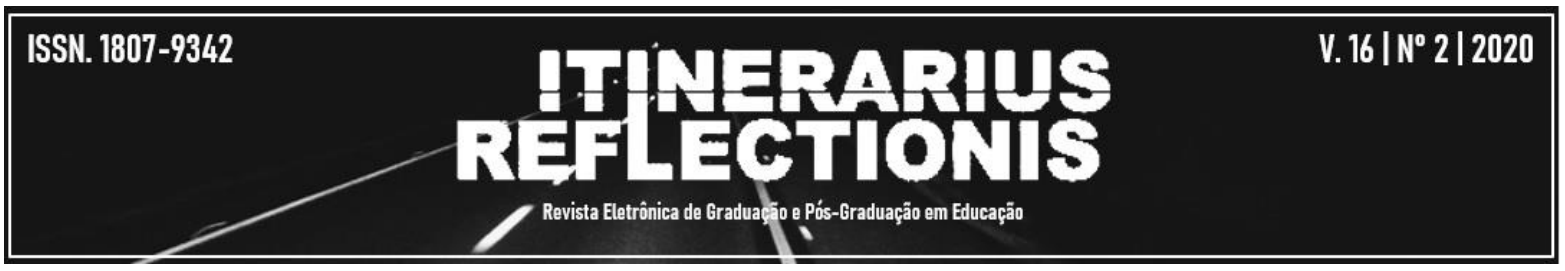

A realidade denota diversos desafios e dificuldades, tanto do ponto de vista operacional, quanto no campo da produção científica, ao passo que a inclusão se encontra inserida na seara do ensino superior, e por que não afirmarmos que essa realidade está aquém do idealizado pelo marco teórico em 1994, na Declaração de Salamanca.

Com o aumento da oferta, verificado ao longo dos anos, pouco se analisou no âmbito das políticas públicas sobre a necessidade de adaptação, existindo na atualidade a discussão sobre a inclusão de vagas nas universidades públicas para estudantes com deficiência à luz das legislações que estiveram em vigor, até então, o que torna latente a necessidade de análise desse contexto à luz da Lei no 13.146/2015.

Essa realidade apresenta ao docente, em formação ou não, um desafio no qual sua perspectiva deverá ser ampliada e atenta para a atual demanda que, em pouco tempo, será cobrada às IES que não se adaptarem.

A nova LBI, $\mathrm{n}^{\circ}$ 13.146/2015, propõe conceitos formalizados a respeito do universo das pessoas com deficiência, seja física ou intelectual, de forma que a sociedade agora está obrigada a dar a devida atenção que esse grupo necessita, nos mais variados ambientes de convivência, o que não exclui o docente de ensino superior da obrigação de se adequar do ponto de vista da sua capacitação, tentando, ao menos, se permitir a lidar com essa proposta desafiadora.

Buscar uma reflexão a respeito das ações governamentais de abrir as portas das universidades para uma demanda latente de pessoas que, segundo leigos no assunto, fogem do que o senso comum chama de normalidade, é uma alternativa que não pode ser descartada. Contudo, é preciso compreender de que forma a docência do ensino superior poderá se adaptar e se capacitar para acolher essa chamada Inclusão Escolar.

\section{A Inclusão Escolar na realidade do ensino superior e a formação do professor}

Discutir o processo de inclusão da educação superior traz à tona a necessidade do educador de se desprender da realidade unicamente voltada para o acesso aos cursos de graduação, traduzindo a urgência de uma construção coletiva que tem origem nos elementos definidores do cotidiano escolar. 




Ao longo das décadas de evolução intelectual da humanidade, nota-se que, principalmente após 1994, evidencia-se um novo e não estranho perfil de demanda acadêmica, onde as pessoas tidas com deficiência começam a despertar interesse pelo ensino superior em maiores números.

No auge da discussão internacional, paralelamente ao tema supramencionado, a Declaração de Salamanca amplia o conceito de ambiente inclusivo, ao definir que:

\begin{abstract}
"Escola Inclusiva é o lugar onde todas as crianças devem aprender juntas, sempre que possível, independentemente de quaisquer dificuldades ou diferenças que elas possam ter, conhecendo e respondendo à necessidades diversas de seus alunos, acomodando ambos os estilos e ritmos de aprendizagem e assegurando uma educação de qualidade a todos através de um currículo apropriado, arranjos organizacionais, estratégias de ensino, uso de recurso e parceria com as comunidades." (UNESCO, 1994).
\end{abstract}

O processo teórico e prático da inclusão na educação superior pode ser um elemento transformador da comunidade acadêmica, uma vez que evidencia soluções para questões sociais se for executado de forma a viabilizar a inserção dos universitários a uma nova realidade, considerando a visão de Vigotski (2001), onde os problemas e soluções vivenciados no cotidiano escolar estão relacionados com tais questões.

No contexto social que acompanha a evolução do ensino superior e a Inclusão Escolar no Brasil, essa expansão educacional vem reforçando seus pilares nas Políticas Públicas, que oportunizam o acesso, tanto físico quanto pedagógico, mas não a qualidade do ensino ofertado, de forma que os críticos e teóricos no assunto remontam a necessidade de reavaliar esse novo paradigma.

Sob a ótica dessa acepção é imprescindível canalizar um processo de qualidade do ensino nas universidades públicas e privadas em todo o país, permitindo que a inclusão esteja diretamente harmonizada com a disponibilidade de vagas aos jovens e grupos excluídos, como também a um processo eficaz na qualificação do ensino superior brasileiro (CUNHA ET AL., 2014).

Dessa forma, é possível enxergar na investigação a realidade que envolve o binômio ensino/formação do docente no ambiente acadêmico superior dentro do universo da Inclusão Escolar, o que remonta o presente discurso a refletir cientificamente sobre a formação do docente e a Inclusão Escolar no ensino superior brasileiro. 




Diante da diversidade que abrange o Ensino Superior no âmbito das Universidades, Centros Universitários, Faculdades Integradas, Faculdades e Institutos Superiores ou Escolas Superiores, nota-se uma distinção latente entre o ensino superior de qualidade e o ensino que converge para uma gestão pautada no aspecto quantitativo.

Aliada a essa realidade, tem-se por limitada a definição de professor capacitado, uma vez que a Lei de Diretrizes e Bases da Educação Nacional delimita o campo da formação de professores sem adentrar a seara do ensino superior.

Entretanto, o exposto no artigo 66, do mesmo diploma, menciona que a preparação para o magistério superior far-se-á em nível de pós-graduação, prioritariamente em programas de mestrado e doutorado e, ao mesmo tempo, nota-se uma delineação de formação continuada dentro da realidade que compreende o ensino superior e certamente não se estabeleceu como local preferencial para a formação dos docentes o nível mais baixo dessa hierarquia.

Convém destacar a visão analítica de Fuches (p. 342, 2012), ao evidenciar a função social das IES, quando aponta o artigo 66, da Lei de Diretrizes e Bases da Educação Nacional, comentando-o de forma abrangente que:

[...] O que a lei exige é que os docentes nas instituições de nível superior sejam formados em cursos de pós-graduação stricto sensu ou lato sensu. A presença de docentes sem especialização pode ser aceita, excepcionalmente, mediante compromisso da instituição no sentido de, em prazo determinado, assegurarem que os docentes adquiram a qualificação mínima.

Em uma análise da Lei de Diretrizes e Bases da Educação Nacional, percebe-se, em sua essência, que o ideal Marxista de todo não é esquecido, uma vez que prioriza o sujeito nas relações ensino-aprendizagem.

Fazendo um comparativo com as realidades europeias mais próximas do nascedouro da Educação Inclusiva (UNESCO, 1994), a presença de docentes sem especialização no ensino superior brasileiro já é um problema grave, ao contrário dos outros modelos verificados no continente europeu, onde se nota algo mais íntimo com o ideal de Inclusão Escolar, geminado com os ditames da declaração de Salamanca, quando se vê, de forma latente, a realidade que envolve especificamente parte da península ibérica. 


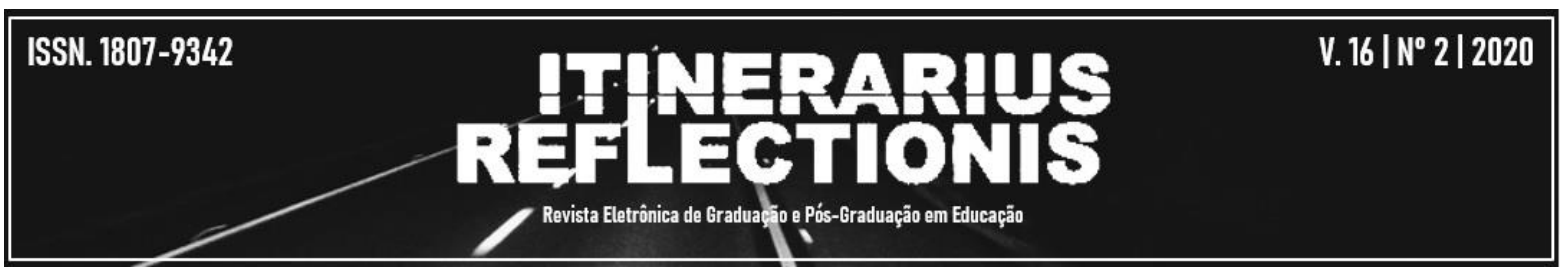

Portugal e Espanha se destacam no processo de formação continuada na seara da Inclusão Escolar quando evidenciam, nos cursos de formação docente, matrizes curriculares estruturadas de forma sequenciada, onde a capacitação nunca dura menos de seis anos, quando o viés da formação converge para uma formação dentro do contexto da Inclusão Escolar.

Os teóricos dos estudos portugueses do assunto reportam a pensar a respeito da realidade brasileira, onde se compreende que aquele panorama encontra-se um pouco distante, no qual, segundo Santos (p. 63, 2015), "o modelo nacional de formação de professores para a educação especial pressupõe a obtenção de habilitação profissional para a docência acrescida de uma formação especializada num domínio de educação especial".

Diante dessa realidade prático-pedagógica que envolve as políticas voltadas ao tema, exprime-se a necessidade de compreender de qual forma a educação brasileira, mais precisamente com relação à formação do docente no ensino superior, poderá se harmonizar com os pensamentos e teorias que, assim como a Declaração de Salamanca (UNESCO, 1994), alicerçam cientificamente a emancipação do docente formado ou em constante formação.

Uma forma eficaz de qualificação no âmbito da educação superior é focar no objetivo pautado na cidadania que estas instituições de ensino superior podem oportunizar a toda a comunidade envolvida, direta e indiretamente, pelo processo de inclusão. Isto porque, segundo Raimann e Guido (p. 4, 2003), “o ensino superior, como espaço/tempo de encontro e de realização do homem, se determina pelo entendimento compartilhado e pela atuação solidária dos que dele fazem parte. [...]".

Desta forma, abre-se um espaço para harmonizar essa dialética com a essência de Freire (2005) e Saviani (2005), ao manter uma reflexão na intenção de compreender se realmente as universidades podem ser um celeiro de constante aprendizado para os docentes em formação, aliada à necessidade de oportunizar uma Inclusão Escolar, emancipatória e libertadora, de forma que as pessoas com deficiência tenham oportunidades justas e isonômicas de acesso ao conhecimento.

Diante das nossas atuais e imaturas potencialidades enquanto produtores do conhecimento científico é importante lembrar que estamos em constante desafio quando o assunto é inclusão dentro do contexto de formação do docente superior que, por si só, 


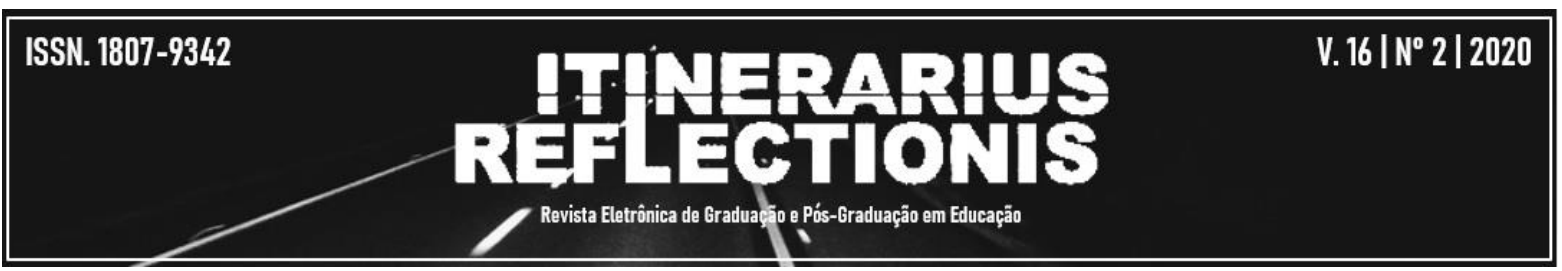

apresenta um espaço de múltiplas realidades, exploradas, apenas, em algumas áreas do conhecimento.

Alguns preferem apontar ser próprio das licenciaturas esse papel sanador, do ponto de vista científico. Porém, quando se trata da Inclusão Escolar, as licenciaturas, em uma simples análise de suas propostas curriculares, mostram-se insuficientes, uma vez que a inclusão propõe um trabalho conjunto e multidisciplinar que apenas uma área do conhecimento não consegue alcançar de forma isolada.

A multidisciplinaridade vem reforçada na Lei $n^{\circ} 13.146 / 2015$ e, paralelamente, é apontada como uma possível solução para o problema da Inclusão Escolar no ensino superior, pelos estudos até então desenvolvidos nos programas de pós-graduação.

\section{CONSIDERAÇÕES FINAIS}

Por tudo que foi elucidado até agora, mostra-se necessário a apropriação e apoio em alguma teoria do pensamento educacional brasileiro, de forma que seja alcançada uma análise científica da temática da educação.

No presente artigo, não foi menos diferente quando optamos por fazer um link entre Paulo Freire, Dermeval Saviani, com o não menos importante pensamento marxista, e as contribuições deste, para que, sob esse olhar, houvesse entendimento quanto à sistemática e dialética realidade que envolve o contexto da formação docente no Brasil, ainda que em breves linhas, assim como a influência que o celeiro de aprendizado que chamamos de universidade pode proporcionar.

Estreita é, ainda, a ponte quando uma produção tem como objetivo analisar este contexto com a demanda da Inclusão Escolar, restando uma "pincelada" para essa reflexão.

É arriscado cogitar a inclusão na educação sem um ensino de qualidade e acessibilidade pedagógica, o que denota a quebra de paradigmas na espinha dorsal da sociedade, transparecendo, assim, a harmonização da relação educação superior com a cidadania e, consequentemente, alcançando a sociedade beneficiada de forma positiva.

$\mathrm{O}$ fato é que essa demanda coloca o ensino superior em si como o ambiente propício a constantes reflexões sobre o papel da universidade na formação do docente, já que há uma 


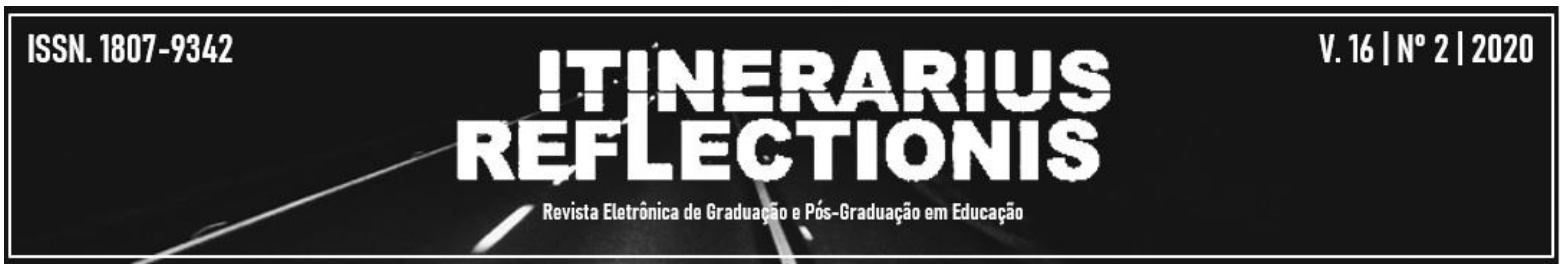

deficiência em programas de formação docente nesse viés, de modo que possa chegar próximo ao idealizado na Declaração de Salamanca (UNESCO, 1994).

Elucidar o espaço universitário e todos os elementos envolvidos a este, direciona o processo de formação de professores para o que muitos definem como dinâmico, onde mesmo não tendo uma formação específica concluída ou estando com formação continuada em andamento, o professor estaria em condições favoráveis ao aprimoramento profissional, tomando como estudos de caso ou aprofundamento no tema as diversas situações que este vivencia no interior da universidade.

Portanto, é nítido o papel que a universidade representa na vida dos docentes que se encontram em formação ou formação continuada, figurando-a como um celeiro de experiências e possibilidades de estudos, com olhares multidisciplinares.

\section{REFERÊNCIAS}

CARMO, Erivaldo Ferreira; CHAGAS, José Aercio Silva; FIGUEIREDO FILHO, Dalson Britto; ROCHA, Enivaldo Carvalho. Políticas públicas de democratização do acesso ao ensino superior e estrutura básica de formação no ensino médio regular. Rev. bras. Estud. pedagog. (online). Brasília. 95(240): 304-327, maio/ago. 2014.

CARVALHO, Ademar de Lima. Os caminhos perversos da educação: a luta pela apropriação do conhecimento no cotidiano da sala de aula. Cuiabá: UFMT, 2005.

CUNHA, Luís Carlos Vieira da; SILVA, Alexandre Rigotti; PLANTULLO, Vicent Lentini; PAIVA, Donizetti Leonidas de. Políticas públicas de incentivo à educação superior brasileira: Acesso, expansão e equidade. Iniciação - Revista de Iniciação Científica, Tecnológica e Artística. 4(4): 1-14, dez. 2014.

FRAUCHES, Celso da Costa. FAGUNDES, Gustavo M; LDB anotada e comentada e reflexões sobre a educação superior. 3 ed., atual. - Brasília: ILAPE, 2012.

FREIRE, Paulo. Pedagogia do Oprimido. Rio de Janeiro. Paz e terra, 42 ed. 2005. . Educação como prática da liberdade. Rio de Janeiro, Paz e Terra, 30 ed.

2007. 


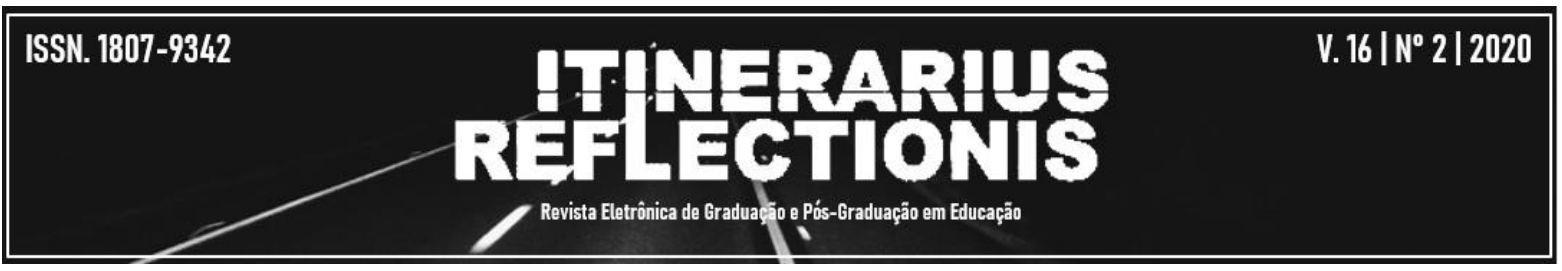

. A educação na cidade. São Paulo Cortez, 62 ed. 2005.

MARX. Karl. Manuscritos econômicos-filosóficos. Lisboa, 1989.

MARX. Karl e ENGELS, F. A ideologia Alemã. São Paulo, Hutitec, 1987.

MARX, Karl. O Capital, Livro I, volume I. São Paulo: Nova Cultural, 1989.

SANTOS, João Adelino Matias Lopes dos. Formação de professores para a educação especial: motivações, expectativas e impacto profissional. Disponível em:

$<$ http://hdl.handle.net/10400.6/3966>. Acesso em 11/01/2018.

SAVIANI, D. Educação: do senso comum à consciência filosófica. 10. Ed. São Paulo: Cortez, 1991. . Escola e Democracia. 39. Ed. Campinas: Autores Associados, 2007.

SAVIANI, Dermeval. O legado educacional do século XX no Brasil. Campinas, SP:

Autores Associados, 2004.

VIGOTSKI, Lev Semyonovich. Psicologia pedagógica. São Paulo: Martins Fontes, 2001. 